\title{
Epidemiological Profile of Childbirth among Primiparous Women in Rural Areas of Tanganyika Province, Democratic Republic of Congo
}

\author{
Héman Kabemba Bukasa1, Teiggy Birhula Mongane², Sylvain Kilima Kunda3, \\ Lutula B'Tient Jean-Jacques Saturnin ${ }^{3,4}$, David Libala Ayumba5, James Kayembe Tube6, \\ Abigaël Mukonkole Kapenga ${ }^{7}$, Jean-Pally Ngoyi-Ngoyi Kampule1, John Ntabo Shebeni ${ }^{8}$, \\ Didier Kasumba Ilunga ${ }^{1}$, Clement Ngindu Ilunga ${ }^{9}$, Ghislain Kalombo Mushinga ${ }^{1}$, Tshite Tshite ${ }^{1}$ \\ ${ }^{1}$ Department of Nursing, Higher Institute of Medical Techniques of Lubao, Lubao, Democratic Republic of Congo \\ ${ }^{2}$ Health Economics, Regional School of Public Health, Catholic University of Bukavu, Bukavu, Democratic Republic of Congo \\ ${ }^{3}$ Management and Administration of Health Institutions, Higher Institute of Medical Techniques of Kalemie, Kalemie, \\ Democratic Republic of Congo \\ ${ }^{4}$ Option of Educational Technologies, Department of Educational Sciences, Faculty of Psychology and Educational Sciences, \\ University of Lubumbashi, Lubumbashi, Democratic Republic of Congo \\ ${ }^{5}$ Department of Nursing, Higher Institute of Medical Techniques of Kalemie, Kalemie, Democratic Republic of Congo \\ ${ }^{6}$ Department of Management of Biomedical Techniques, Higher Institute of Medical Techniques of Manono, Manono, \\ Democratic Republic of Congo \\ ${ }^{7}$ Department of Nutrition Sciences, Higher Institute of Medical Techniques of Manono, Manono, Democratic Republic of Congo \\ ${ }^{8}$ Department of Nursing, Higher Institute of Medical Techniques of Walikale, Walikale, Democratic Republic of Congo \\ ${ }^{9}$ University of Lubumbashi, Lubumbashi, Democratic Republic of Congo \\ Email: *hemanuska@gmail.com
}

How to cite this paper: Bukasa, H.K., Mongane, T.B., Kunda, S.K., Saturnin, L.B.J.-J., Ayumba, D.L., Tube, J.K., Kapenga, A.M., Kampule, J.-P.N.-N., Shebeni, J.N., Ilunga, D.K., Ilunga, C.N., Mushinga, G.K. and Tshite, T. (2021) Epidemiological Profile of Childbirth among Primiparous Women in Rural Areas of Tanganyika Province, Democratic Republic of Congo. Open Access Library Journal, 8: e7243.

https://doi.org/10.4236/oalib.1107243

Received: February 13, 2021

Accepted: March 28, 2021

Published: March 31, 2021

\begin{abstract}
Introduction: Sub-Saharan Africa remains one of the areas where maternal deaths are most prevalent. This situation is linked to a number of maternal risk factors including obstetric experience, age, disease history, socio-economic conditions and the quality of the health system. The objective of this study is to determine the epidemiological profile of childbirth in rural primiparous women. Methods: This is a multi-centre, retrospective and descriptive cross-sectional study among primiparous women in Moba (DR. Congo). The period from 2015 to 2016 was chosen. Epi Info 7 and Excel software were used for data analysis. Results: Of the 2644 deliveries selected for this study, $474(17.9 \%)$ were among primiparous women. The average age of primiparous women was $18.4 \pm 1.9$ years (extremes 15 to 24 years). The majority of primiparous women were educated, married, housewives, with poor prenatal
\end{abstract}


Copyright $\odot 2021$ by author(s) and Open Access Library Inc.

This work is licensed under the Creative Commons Attribution International License (CC BY 4.0).

http://creativecommons.org/licenses/by/4.0/ monitoring of pregnancies, having given birth by eutocic mode (53.6\%) and vaginal route (92.0\%). Maternal and early neonatal mortality was $0.8 \%$ and $1.7 \%$ respectively. This mortality only significantly $(\mathrm{p}<0.05)$ concerned dystocic deliveries and the 18- to 21-year-old age group. Maternal age ( $p<0.001)$, especially before the age of $18(\mathrm{p}<0.000)$, and occupation $(\mathrm{p}<0.01)$ significantly determine the mode of childbirth. Conclusion: The primiparous under 18 years of age presents risks of dystocic childbirth. Dystocia is responsible for several complications that can lead to maternal or neonatal death. Efforts should be made to discourage early pregnancy and improve the quality of obstetric care.

\section{Subject Areas}

Epidemiology, Gynecology \& Obstetrics, Public Health

\section{Keywords}

Childbirth, Epidemiology, Primiparous, DRC

\section{Introduction}

Maternal and child health occupies an important place in each country's health development plans (HDPs). Childbirth is the set of mechanical (uterus, foetus, maternal pelvis) and physiological phenomena that result in the foetus and its appendages leaving the genital tract from the age of viability [1] [2]. It remains a mystery of reproduction that has fascinated humans since ancient times [3] and constitutes an essential and final stage of pregnancy with a gestational age of at least 22 or 28 weeks of amenorrhoea (SA) [2] [4].

The course of childbirth depends on a number of factors including obstetrical experience (gestational age, parity), maternal age, surgical history, nature of uterine contractions, position of the foetus in utero, etc. [5] [6] [7] [8]. In the context of this study, it concerns deliveries of primiparous women.

A primiparous woman is defined as a woman giving birth for the first time [7] [9]. She occupies an important place in the transition to obstetric experiences for every woman.

Indeed, the first pregnancy and the first birth are real public health problems given the seriousness of the facts surrounding them. Several studies have established links between parity and the occurrence of certain morbid circumstances in the mother (caesarean section, depression, lesion of the perineum, eclampsia, etc.) and the foetus (prematurity, low birth weight, congenital malformations, etc.) [6] [7] [10] [11] [12] [13]. As a result, primiparity is a high-risk factor for pregnancy and childbirth, especially in developing countries and countries south of the Sahara such as the Democratic Republic of Congo [7] [13] [14].

Indeed, in developing countries, the quality of obstetric care is not always satisfactory and maternal and infant mortality rates remain very high [7] [15] [16]. This makes it imperative to undertake efforts to improve the quality of obstetric- 
al care and thus achieve the 2016-2030 objectives of sustainable development, as a logical follow-up to the Nairobi conference on maternal mortality.

In a study conducted in urban Lubumbashi (DR Congo) from 2013 to 2014, the authors concluded that "the delivery of primiparas remains an obstetric problem" [7].

It is within this framework that this study was finally initiated to contribute to the health of mother and child. The aim of this study is to determine the epidemiological profile of childbirth among primiparous women in rural areas, particularly in the city of Moba, Tanganyika province, in the Democratic Republic of Congo.

\section{Methodology}

\subsection{Setting, Type and Period of Study}

This study is multi-centric, retrospective and cross-sectional descriptive at the same time. It was carried out in two hospitals in the city and territory of Moba (Tanganyika province, south-eastern DRC) over a period of two years, from 2015 to 2016: Katombe Health Centre and Moba General Reference Hospital (HGR) in the rural commune of Kirungu. These two health structures are an integral part of the Moba health zone.

The Moba General Hospital, located in the rural commune of Kirungu, is the largest reference structure in the Moba territory $\left(24,500 \mathrm{Km}^{2}\right.$ and 609,406 inhabitants) and covers two health zones: Kansimba and Moba. The population lives mainly from agriculture and fishing on Lake Tanganyika.

In terms of human resources, almost all levels of education are found there (A3, A2 and A1) among the providers. However, only the HGR in Moba has general practitioners. The Moba HGR maternity hospital has a capacity of 18 beds.

\subsection{Study Population}

Our study population was made up of births that had attended the maternity wards of the Katombe and HGR health centre in Moba. The sample was exhaustive and systematic throughout the period covered by this study, i.e. 474 women. Any woman who had given birth in these facilities during the period in question and who had collected the study variables was included. The data collection for this study was carried out on the basis of antenatal care (ANC) registers, birth registers and partograms.

\subsection{Study Variables (Parameters)}

For this study, the following information was sought for each selected birth: age, level of education, marital status, occupation, parity, number of antenatal care (ANC) followed during pregnancy, types and modes of delivery (eutocic or dystocic), routes of delivery (high or low), the evolution of post-partum births and of newborns in the early neonatal period.

On the subject of parity, we distinguish, according to obstetrical experiences: The Primiparous: 1 delivery; the Pauciparous: 2 - 3 deliveries; the Multiparous: 4 
- 6 deliveries; and the Grand Multiparous: at least 7 deliveries.

Data was collected from birth registers, partograms and for some women interviews were necessary.

\subsection{Data Processing and Statistical Analysis}

The data collected on a pre-established form for our study were encoded on the Excel spreadsheet (Microsoft, version 2010, USA) to be imported into the Epi Info 7.1 software (Center for Disease control and prevention, Atlanta, USA, 2012) [17]. Descriptive analysis of the results was carried out to obtain the frequency (percentage) of deliveries in primiparous women and the parameters of position and dispersion (mean, extremes, median, standard deviation). The relationships between the variables studied were assessed using p-value. The significance threshold was chosen at $\leq 0.05$ for the alpha error.

\subsection{Research Ethics}

The principles of scientific research had been respected during this study. In the absence of a structure in charge of regulating universal measures of research ethics in biomedical sciences, we had obtained the authorisations of the managers of the structures concerned by this study (Katombe Health Centre and the gynaecology and obstetrics department of the Moba General Reference Hospital). The anonymity of the identities and information obtained from the women's medical records had been respected.

\section{Results}

\subsection{Frequency and Socio-Demographic Characteristics of Primiparous Women}

During the period of our study, 2644 births were recorded. The majority of deliveries were multiparous $(n=1310$ or $49.5 \%)$ followed by pauciparous $(n=534$ or $20.5 \%)$, primiparous $(n=474$ or $17.9 \%)$ and large multiparous $(n=306$ or $11.6 \%)$. Thus, the frequency of primiparity in our study series was $17.9 \%$ (Figure 1).

According to Table 1, the majority of births were between 18 and 21 years of age, with an overall average of $18.4 \pm 1.9$ years and extremes of 15 to 24 years. Minor mothers, i.e. under 18 years of age, were represented at $33.3 \%$ ( $n=158$ and $14-17$ years of age). In $79.7 \%(n=378)$, the births were at secondary school level (post-primary). Married women were the most common ( $\mathrm{n}=344$ or $72.6 \%$ ). With regard to occupation, housewives in the home were the most encountered $(n=342$ or $72.2 \%)$ and students $18.1 \%(n=86)$.

\subsection{Monitoring of ANCs by Primiparous}

According to Table 2, the majority of births were attended by ANC, $98.3 \%$ ( $\mathrm{n}=$ 466) compared to $1.7 \%(n=8)$ who did not attend ANC. Births with a single ANC ( $\mathrm{n}=222$ or $46.8 \%$ ) were the most represented, followed by two ANCs ( $\mathrm{n}=$ 160 or $33.8 \%$ ) and three ANCs ( $\mathrm{n}=84$ or $17.7 \%$ ). No woman had achieved 4 ANCs during the gestational period. The average ANC was $1.7 \pm 0.8$. 


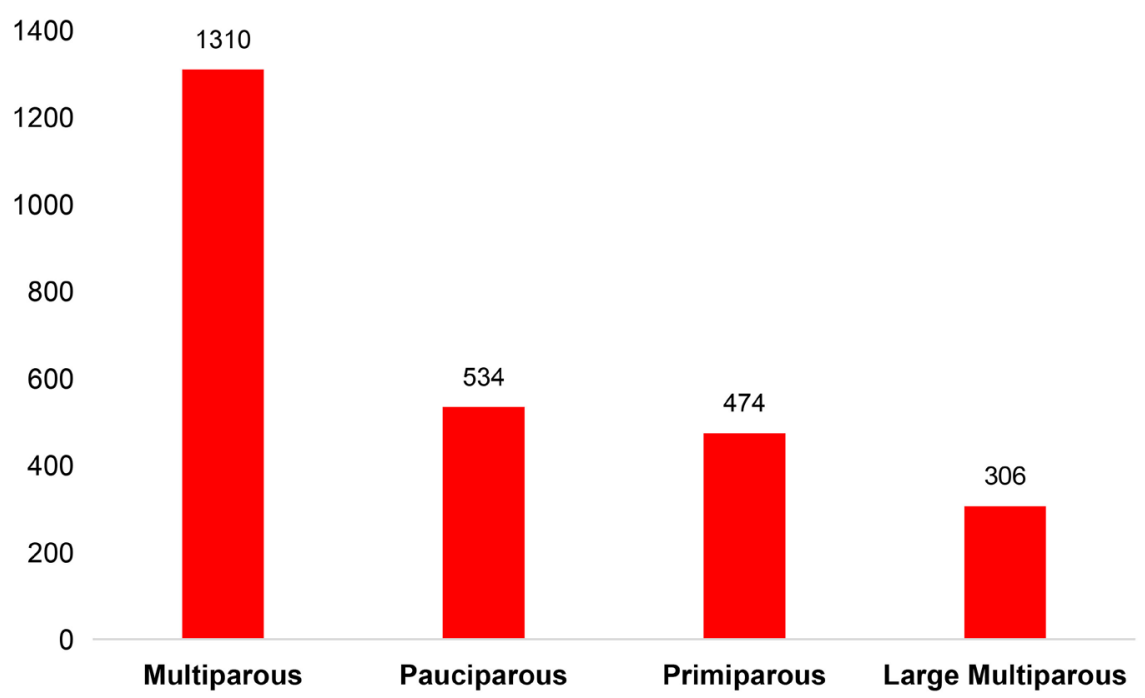

Figure 1. Parity of women $(\mathrm{n}=2644)$.

Table 1. Socio-demographic characteristics and modes of delivery.

\begin{tabular}{|c|c|c|c|c|}
\hline \multirow[b]{2}{*}{ Characteristics } & \multicolumn{4}{|c|}{ Types or modes of childbirth (Deliveries) } \\
\hline & $\begin{array}{l}\text { Total } \\
\text { n (\%) }\end{array}$ & $\begin{array}{c}\text { Eutocic } \\
\text { n (\%) }\end{array}$ & $\begin{array}{c}\text { Dystocic } \\
\text { n (\%) }\end{array}$ & p-value \\
\hline \multicolumn{5}{|l|}{ Age (Years) } \\
\hline $14-17^{\star}$ & $158(33.3)$ & $66(41.8)$ & $92(58.2)$ & \\
\hline $18-21$ & $286(60.3)$ & $170(59.4)$ & $116(40.6)$ & \\
\hline $22-25$ & $30(9.3)$ & $18(60.0)$ & $12(40.0)$ & \\
\hline Total & $474(100)$ & $254(53.6)$ & $220(46.4)$ & 0.0007 \\
\hline Median & 18.4 & 19.5 & 18.5 & \\
\hline Average (Means) & 18.4 & 18.7 & 18.1 & \\
\hline $\mathrm{SD}^{* *}$ & 1.9 & 1.9 & 2 & \\
\hline Extremes & $15-24$ & $16-24$ & $15-23$ & \\
\hline \multicolumn{5}{|l|}{ Level of education } \\
\hline Illiterate & $18(3.8)$ & $10(55.6)$ & $8(44.4)$ & \\
\hline Primary & $78(16.5)$ & $34(43.6)$ & $44(56.4)$ & 0.2072 \\
\hline Secondary & $378(79.7)$ & $210(55.6)$ & $168(44.4)$ & \\
\hline Higher and university & - & - & - & \\
\hline \multicolumn{5}{|l|}{ Marital status } \\
\hline Single & $130(27.4)$ & $72(55.4)$ & $58(44.6)$ & 0.6303 \\
\hline Married & $344(72.6)$ & $182(52.9)$ & $162(47.1)$ & \\
\hline \multicolumn{5}{|l|}{ Profession } \\
\hline Housewife at home & $342(72.2)$ & $188(55.0)$ & $154(45.0)$ & \multirow{4}{*}{0.0072} \\
\hline Student & $86(18.1)$ & $48(55.8)$ & $38(44.2)$ & \\
\hline Teacher & $12(2.5)$ & $4(33.3)$ & $8(66.7)$ & \\
\hline Cultivator & $8(1.7)$ & $4(50.0)$ & $4(50.0)$ & \\
\hline
\end{tabular}




\section{Continued}

\begin{tabular}{cccc}
\hline Trader & $4(0.8)$ & - & $4(100)$ \\
None & $12(2.5)$ & - & $12(100)$ \\
Undetermined & $10(2.1)$ & $10(100)$ & -
\end{tabular}

${ }^{\star} 14-17$ and $18-25$ years old: p 0.0000; SD**: Standard deviation.

Table 2. ANC monitoring and types of deliveries.

\begin{tabular}{ccccc}
\hline ANC & Total n (\%) & Deliveries n (\%) & p-value \\
\cline { 1 - 2 } None & $8(1.7)$ & Eutocic & Dystocic & \\
1 & $222(46.8)$ & $132(59.5)$ & $90(40.5)$ & 0.5185 \\
2 & $160(33.8)$ & $78(48.8)$ & $82(51.2)$ & \\
3 & $84(17.7)$ & $44(52.4)$ & $40(47.6)$ & \\
4 & - & - & - & \\
Total & $474(100)$ & $254(53,6)$ & $220(46,4)$ & \\
\hline
\end{tabular}

Means: $1.7 \pm 0.8$

Table 1 shows that eutocic births were the most represented compared to dystocic births ( 254 or $53.6 \%$ vs. 220 or $46.4 \%$ ). Dystocic births were more common in the $14-17$ age group ( $\mathrm{n}=92$ out of 158 or $58.2 \%$ ) with an average of 18.5 \pm 2 and extremes of $15-23$ years. Eutococcal births were mainly found among those aged 18 and over (18 to 24 years) with an average of $18.7 \pm 1.9$ years and extremes of 13 to 24 years.

Compared to the delivery route in primiparous women, the lower route was significantly $(\mathrm{p}<0.05)$ the most used $(\mathrm{n}=436$ or $92.0 \%)$ compared to $8.0 \%(\mathrm{n}=$ 38 ) for the upper route or caesarean section (Figure 2). The age ( $p$ 0.0007) and the occupation ( $\mathrm{p} \mathrm{0.0072)}$ of the births determine the mode of delivery.

\subsection{Deliveries in Primiparous Women}

Table 1 shows that eutocic births were the most represented compared to dystocic births ( 254 or $53.6 \%$ vs. 220 or $46.4 \%$ ). Dystocic births were more common in the $14-17$ age group ( $\mathrm{n}=92$ out of 158 or $58.2 \%$ ) with an average of $18.5 \pm 2$ and extremes of 15 - 23 years. Eutococcal births were mainly found among those aged 18 and over (18 to 24 years) with an average of $18.7 \pm 1.9$ years and extremes of 13 to 24 years.

Compared to the delivery route in primiparous women, the lower route was significantly $(\mathrm{p}<0.05)$ the most used $(\mathrm{n}=436$ or $92.0 \%)$ compared to $8.0 \%(\mathrm{n}=$ 38 ) for the upper route or caesarean section (Figure 2). The age ( $p$ 0.0007) and the occupation ( $\mathrm{p} \mathrm{0.0072)}$ of the births determine the mode of delivery.

\subsection{Evolution of Primiparous and Newborns (Early Neonatal Period)}

According to Table 3, in the majority of cases the evolution was good for 


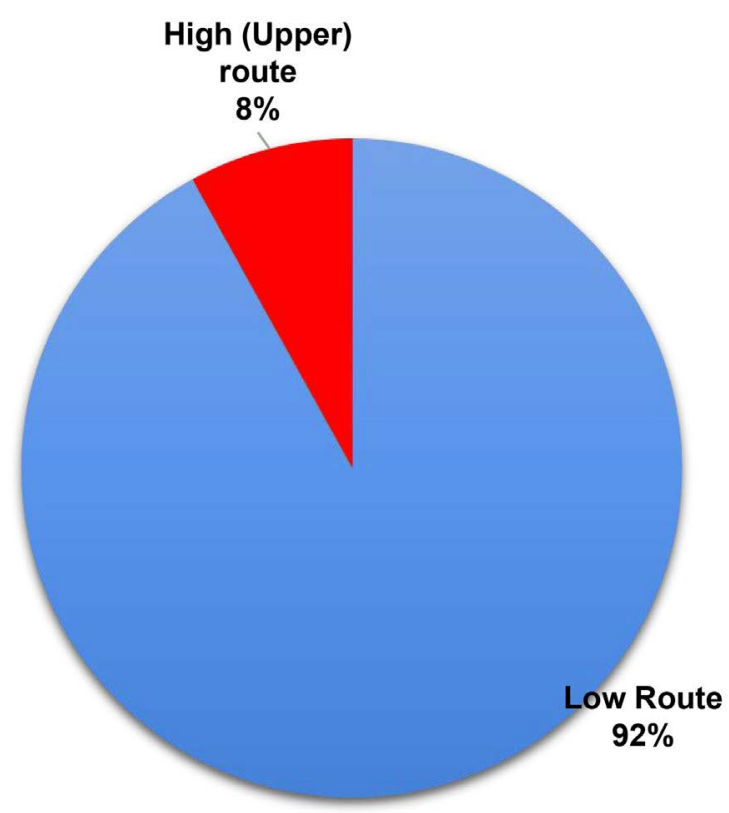

Figure 2. Pathway of delivery $(\mathrm{n}=474) ; \mathrm{p}<0.05$.

Table 3. Types of childbirth and maternal-neonatal evolutions (early).

\begin{tabular}{|c|c|c|c|c|c|c|c|c|}
\hline \multirow[t]{2}{*}{ Delivery Modes } & \multicolumn{4}{|c|}{ Mother n (\%) } & \multicolumn{4}{|c|}{ Newborn n (\%) } \\
\hline & Good & $\mathrm{Bad}^{* *}$ & Death & $\mathrm{P}-\mathrm{v}^{*}$ & Good & $\mathrm{Bad}^{\dagger}$ & Death & $P-v^{*}$ \\
\hline $\begin{array}{c}\text { Eutocic } \\
\mathrm{n}=254(\%)\end{array}$ & $\begin{array}{c}222 \\
(87.4)\end{array}$ & $\begin{array}{c}32 \\
(12.6)\end{array}$ & - & & $\begin{array}{c}236 \\
(92.9)\end{array}$ & $\begin{array}{c}18 \\
(7.1)\end{array}$ & - & \\
\hline $\begin{array}{c}\text { Dystocic } \\
\mathrm{n}=220(\%)\end{array}$ & $\begin{array}{c}164 \\
(74.5)\end{array}$ & $\begin{array}{c}52 \\
(23.6)\end{array}$ & $\begin{array}{c}4 \\
(1.8)\end{array}$ & $S^{* * *}$ & $\begin{array}{c}132 \\
(60.0)\end{array}$ & $\begin{array}{c}80 \\
(36.4)\end{array}$ & $\begin{array}{c}8 \\
(3.6)\end{array}$ & $S^{* * * *}$ \\
\hline $\begin{array}{c}\text { Total } \\
\mathrm{n}=\mathbf{4 7 4}(\%)\end{array}$ & $\begin{array}{c}386 \\
(81.4)\end{array}$ & $\begin{array}{c}84 \\
(17.7)\end{array}$ & $\begin{array}{c}4 \\
(0.8)\end{array}$ & & $\begin{array}{c}368 \\
(77.6)\end{array}$ & $\begin{array}{c}98 \\
(20.7)\end{array}$ & $\begin{array}{c}8 \\
(1.7)\end{array}$ & \\
\hline
\end{tabular}

p- $\mathbf{v}^{*}$ : p-value; ${ }^{* *}$ : Postpartum haemorrhage, puerperal infection, tear of the perineum, tear of the cervix, etc.; $S^{* * *}$ : Significant $0.0205 ; S^{* * * *}$ : Significant $0.0001 ; \dagger$ : Respiratory distress, anemia, hypoglycemia, etc.

primiparous mothers $(\mathrm{n}=386$ or $81.4 \%)$ and their newborns $(\mathrm{n}=368$ or $77.6 \%)$ during the neonatal period. In $17.7 \%(n=84)$ and $20.7 \%(n=98)$ of cases, the evolution was bad, respectively for primiparous and newborn babies. Respiratory distress, anaemia and hypoglycaemia for newborns and delivery haemorrhages, puerperal infections, tears of the perineum and cervix, etc. for primiparous women were among the morbid elements that had favoured this poor evolution in our series (Table 3 ).

Mortality was $1.7 \%(\mathrm{n}=8)$ for newborns and $0.8 \%(\mathrm{n}=4)$ for primiparous women. All postpartum and early neonatal maternal deaths were recorded in the category of dystocic deliveries (Table 3).

The mode of delivery was determinant in maternal ( $p$ 0.0205) and early neonatal ( $p$ 0.0001) outcomes. On the other hand, maternal age was not associated with neonatal ( $p$ 0.4194) and maternal mortality ( $p$ 0.5591). All of the eight newborn deaths occurred in mothers aged 18 - 21 years (Figure 3 and Figure 4). 
300

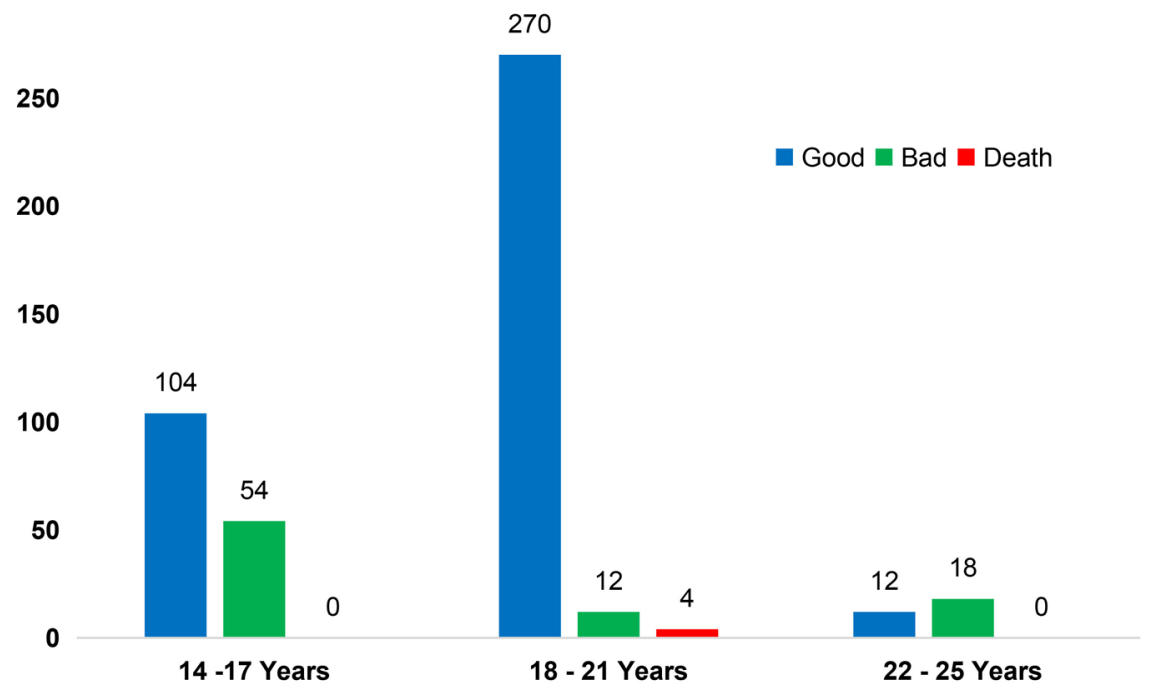

Figure 3. Maternal age and evolution $(\mathrm{n}=474)$; $\mathrm{p}$-value $=0.5591$.

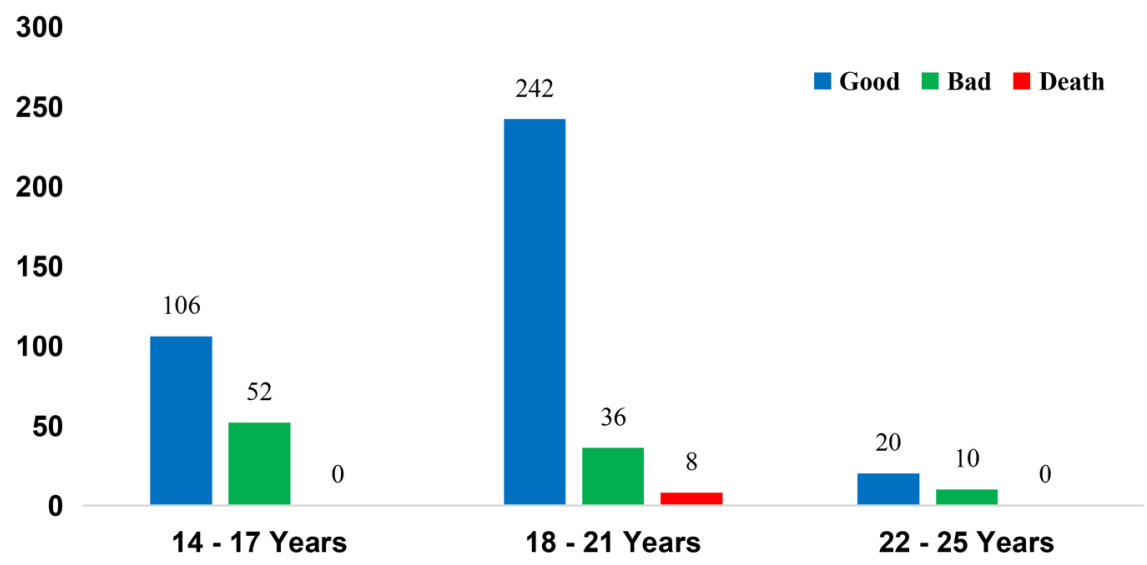

Figure 4. Maternal age and evolution of the newborn during the early neonatal period ( $\mathrm{n}$ $=474) ; \mathrm{p}$-value $=0.4194$.

\section{Discussion}

Primiparity remains an important period in every woman's obstetric experience. Primiparous mothers are a high-risk group during pregnancy and childbirth, as evidenced by several scientific studies [5] [7] [13] [18] [19]. Good control of the factors associated with this risk is necessary to significantly reduce morbidity and mortality.

In Moba, deliveries by primiparous women account for $17.9 \%$ of all hospital deliveries. Indeed, the frequency of women having their first experience of childbirth varies from one country to another.

In Lubumbashi (Democratic Republic of Congo), Munan et al. [7] reported 19.9\% while Okunade et al. [20] in Lagos, Nigeria reported 15.3\%. The results of these two studies are close to our findings regarding the frequency of primiparity. On the other hand, Danish et al. [21] found 27.3\% of primiparous births; and Latif et al. [22] in Bangladesh (a developing country such as the Democratic Re- 
public of Congo) there were 500 primiparous births out of 1250 births, or $40 \%$. The difference in frequencies would be related to the birth reporting system, the study methodology and the behaviour of multiparous women. In fact, the latter tend to minimise the obstetrical risk of giving birth in hospital and most prefer to give birth at home. Several studies confirm this thesis and also evoke the fear of the primiparous as a result of their obstetrical inexperience, which in part obliges them to visit health services more frequently [7] [23] [24] [25].

The socio-demographic profile is dominated by primiparous women aged between 18 and 21 with an average age of $18.4 \pm 1.9$ years, married, educated up to secondary school level, and housewife. In fact, the age of first obstetric experience is closely linked to the sociological, cultural and economic environment. It is lower in rural than in urban areas because living conditions, easy access to modern contraceptive methods and high educational attainment tend to delay the age of marriage [26] [27] [28].

Under-age girls, under the age of 18 , represent $33.3 \%$ of primiparous women, which should be of concern to political and health decision-makers. The protection of young girls in the fight against early marriages and sexual violence would help to reduce the high frequency of childbirths among girls under 18, given that $18.1 \%$ of primiparous girls were schoolchildren.

The majority of primiparas attended antenatal clinics, $98.3 \%$. No woman had attended four antenatal consultations during pregnancy, which demonstrates poor management of pregnancies. Efforts still need to be made to improve the preventive care of high-risk pregnancies in general and particularly for this category of pregnant and parturient women [2] [7] [25].

In this series of studies, dystocic births represent $46.4 \%$ with predominance in the 14 to 17 age group, which bears witness to the young primiparas in our study series. Indeed, the rural environment is characterised by early marriages and unwanted pregnancies [1] [28] [29] [30], and Moba is no exception to this logic.

Eutocic deliveries account for $53.6 \%$ and mainly women up to the age of 18 . And $92 \%$ of primiparous women gave birth by the vaginal route, caesarean sections cover only $8 \%$. In view of these results, it appears that a non-negligible proportion of women had dynamic dystocia. These results corroborate those already mentioned in the medical and scientific literature [7] [16] [24].

Age was a significant determinant in the mode of childbirth, eutocic or dystocic. It is an obstetrical risk factor mentioned in several studies [2] [28] [29] [30], which should draw our attention and that of the political and health authorities to the need to combat early marriage and unwanted pregnancies.

The problem of the relationship between parity and obstetric complications is of interest to obstetricians. On the one hand, there are those who maintain that parity is a risk factor, and on the other hand there are obstetricians who limit the risks of complications related to parity. We are in harmony with the first group, as evidenced by several studies [7] [27] [28] [29] [30] and hospital obstetrical experiences, especially in developing countries.

The majority of primiparas and newborns had progressed well during the first 
week, with $81.4 \%$ and $77.6 \%$ respectively. This is encouraging. However, the frequency of complications is worrying.

Among the complications encountered in primiparous births are delivery haemorrhages, puerperal infections, tearing of the perineum and tearing of the cervix. These have been mentioned by some authors and are closely related to dystocia [10] [22] [25].

This poor development, characterized by complications, was the cause of four deaths among primiparous women, i.e. $0.8 \%$. This result testifies to the permanent risk to which the primiparous woman in rural areas is exposed, contrary to the main objective of modern obstetrics: "a woman cannot die as a result of her will to give life".

Among newborns, the morbid evolution was characterised by respiratory distress, anaemia and hypoglycaemia. These complications led to a mortality rate of $1.7 \%$, or eight newborns. To combat this morbidity and mortality, well-equipped neonatal care services must be put in place.

In this study, the results show that the mode of delivery has a significant influence on maternal and neonatal mortality. On the other hand, the age of the primiparous does not determine mortality, which should draw our attention to the quality of care for primigravidae and primiparas in our environment. According to the World Health Organization, WHO, "approximately 15\% of women develop a complication during pregnancy that requires the intervention of a qualified health care provider [31]". In our context, the public authorities should assign obstetricians to take care of women, from pregnancy to the return from childbirth. It is not normal that a population of more than 400 thousand inhabitants lacks specialists, especially in such a complex area as the management of maternal and child health.

\section{Limitations of This Study}

The limitations of this study lie in the lack of comparison with the control group, which can be multiparous. The data that constituted the results of this study were retrospective, which implies that certain parameters were not retained because they were not included in the partograms (in some cases poorly or incompletely filled in). It is therefore important that subsequent studies take these elements into account.

\section{Conclusions}

Maternal and neonatal mortality remains a public health problem, especially in developing countries such as the Democratic Republic of Congo. The main contribution and practical importance of this study are demonstrated by the results encountered.

In this series of studies, childbirth of primiparous women accounts for $17.9 \%$. The majority are primiparous women aged between 15 and 24 years old with an average of $18.4 \pm 1.9$ years, post-primary level, married and housewives in the 
home who have attended mostly ANC with an average of $1.7 \pm 0.8$ sessions. Childbirth of primiparous women in rural areas is characterized by dystocia (46.4\%) and high risks of morbidity and mortality (maternal and neonatal). The results of this study make it possible to strengthen the fight against early marriages and sexual violence against minors, the adequate follow-up of pregnancies (especially those known as high-risk pregnancies) and the improvement of our capacities for the management and obstetric care of women.

\section{Funding}

This study did not receive any external funding. It was funded by contributions from the authors.

\section{Acknowledgements}

The authors would like to thank the nurses of the Katombe Health Centre, Kirungu General Reference Hospital (MOBA) and Mr. NGIELE MPOSHI Djolin (General Academic Secretary of the Higher Institute of Medical Techniques of Lubao) for their contributions in carrying out this study.

\section{Conflicts of Interest}

The authors do not declare any conflict of interest in relation to this study.

\section{References}

[1] Kabemba, B.H., Alimasi, Y., Ntambwe, A., Kalamba, M., Kitenge, F., Nyongonyi, O. and Monzi, H. (2018) Adolescent Pregnancy and Delivery in the Rural Areas of DR. Congo: A Cross-Sectional Descriptive Study (2014 to 2016). Open Access Library Journal, 5, 1-20. https://doi.org/10.4236/oalib.1104762

[2] Hamada, H., Zaki, A., Nejjar, H., Filali, A., Chraibi, C., Bezad, R., et al. (2004) Grossesse et accouchement chez l'adolescente: Caractéristiques et profil. Journal de Gynécologie Obstétrique et Biologie de la Reproduction, 33, 607-614. https://doi.org/10.1016/S0368-2315(04)96601-X

[3] Sills, E.S., Baum, J.D., Ling, X., Harper, M.M., Levy, D.P. and Lockwood, C.J. (1997) Durée moyenne du travail spontané chez les primipares chinoises. Journal de Gynécologie Obstétrique et Biologie de la Reproduction, 26, 704-710.

[4] Kabemba, B.H., Kasendue, E., Shiku, M., Kabingie, N., Ngiele, M., Kitengie, T., et al. (2017) Frequency and Early Neonatal Mortality Related to Anomalies of Birth Weight and Gestational Age in Rural Areas: A Case of the General Reference Hospital of Lubao (Lomami Province, Democratic Republic of Congo). Open Access Library Journal, 4, 1-12. https://doi.org/10.4236/oalib.1103433

[5] Vogel, J.P., Chawanpaiboon, S., Moller, A.B., Watananirun, K., Bonet, M. and Lumbiganon, P. (2018) The Global Epidemiology of Preterm Birth. Best Practice \& Research Clinical Obstetrics and Gynaecology, 52, 3-12. https://doi.org/10.1016/j.bpobgyn.2018.04.003

[6] Lowe, N.K. (2007) A Review of Factors Associated with Dystocia and Cesarean Section in Nulliparous Women. Journal of Midwifery Women's Health, 52, 216-228. https://doi.org/10.1016/j.jmwh.2007.03.003

[7] Munan, R., Kakudji, Y., Nsambi, J., Mukuku, O., Maleya, A., Kinenkinda, X. and 
Kakudji, P. (2017) Childbirth among Primiparous Women in Lubumbashi: Maternal and Perinatal Prognosis. Pan African Medical Journal, 28, 77. https://doi.org/10.11604/pamj.2017.28.77.13712

[8] Tietche, F., Ngoufack, G., Kago, I., Mbonda, E., Koki Ndombo, P.O. and Leke, R.I. (1998) Facteurs étiologiques associes au retard de croissance intra-utérine à Yaoundé (Cameroun): Étude préliminaire. Médecine d’ Afrique Noire, 45, 377-380.

[9] Tebeu, P.M., Obama, M.T., Fodjo Nghonguia, M., Major, A.L., Kouam, L. and Doh, A.S. (2008) Primipare âgée: Du concept à la définition d'une méthode de détermination. Médecine d Afrique Noire, 55, 8-9.

[10] Adriana, A.F., Mirian, H.K., Caroline de Souza, B., Renata Luana da Silva, Edilaine de Paula Batista, M. and Sonia Maria Junqueira Vasconcellos de Oliveira (2014) Association between Perineal Trauma and Pain in Primiparous Women. The University of São Paulo Nursing School Journal (Revista da Escola de Enfermagem da USP), 48, 39-44. https://doi.org/10.1590/S0080-623420140000600006 https://www.scielo.br/pdf/reeusp/v48nspe/0080-6234-reeusp-48-esp-040.pdf

[11] Chami, H.W., Gueye, M., Ndiaye, M.D., Wade, M., Diouf, A., Diakhate, A., Ndour, Si.B., Niang, N. and Mbaye, M. (2019) Relation between Obstetric Outcome and Parity. Open Journal of Obstetrics and Gynecology, 9, 894-903. https://doi.org/10.4236/ojog.2019.96087

[12] Low, L., Zielinski, R., Tao, Y., Galecki, A., Brandon, C. and Miller, J. (2014) Predicting Birth-Related Levator Ani Tear Severity in Primiparous Women: Evaluating Maternal Recovery from Labor and Delivery (EMRLD Study). Open Journal of $\mathrm{Ob}$ stetrics and Gynecology, 4, 266-278. https://doi.org/10.4236/ojog.2014.46043

[13] Martínez-Galiano, J.M., Hernández-Martínez, A., Rodríguez-Almagro, J., Delgado-Rodríguez, M. and Gómez-Salgado, J. (2019) Relationship between Parity and the Problems That Appear in the Postpartum Period. Scientifics Report, 13, Article No. 11763. https://doi.org/10.1038/s41598-019-47881-3

[14] Bouafia, N., Mahjoub, M., Nouira, A., Ben Aissa, R., Saïdi, H., Guedana, N. and Njah, M. (2013) Profil épidémiologique des grossesses à risque à Sousse (Tunisie). Eastern Mediterranean Health Journal, 9, 12-15.

[15] Kungwimba, E., Malata, A., Maluwa, A. and Chirwa, E. (2013) Experiences of Women with the Support They Received from Their Birth Companions during Labour and Delivery in Malawi. Health, 5, 45-52. https://doi.org/10.4236/health.2013.51007

[16] Elrishi, F., Suliman, R. and Elrishi Fatheia, A. (2015) Seven Years Consecutive Cesarean Section in Primigravidae: Analysis and Evaluation. Journal of Medical Science and Clinical Research, 3, 6031-6041.

[17] Dean, A.G., Arner, T.G., Sangam, C.G., Sunki, G.C., Friedman, R., Lantinga, M., et al. (2011) Epi InfoTM, a Database and Statistics Program for Public Health Professionals. Centers for Disease Control and Prevention, Atlanta.

[18] Adeyemi, A.S., Adekanle, D.A. and Afolabi, A.F. (2014) Predictors of Vaginal Delivery in Nulliparous Mothers. Annals of African Medicine, 13, 35-40. https://doi.org/10.4103/1596-3519.126949

[19] Hashim, N., Naqvi, S., Khanam, M. and Hassan Fatima, J. (2012) Primiparity as an Intrapartum Obstetric Risk Factor. Journal of the Pakistan Medical Association, 62, 694-698. https://jpma.org.pk/article-details/3555?article id=3555

[20] Okunade, K.S., Okunola, H., Oyeneyin, L. and Habeeb-Adeyemi, F.N. (2016) Cross-Sectional Study on the Obstetric Performance of Primigravidae in a Teaching Hospital in Lagos, Nigeria. Nigeria Medical Journal, 57, 303-306. 
https://www.ncbi.nlm.nih.gov/pmc/articles/PMC5036303 https://doi.org/10.4103/0300-1652.190595

[21] Danish, N., Fawad, A. and Abbasi, N. (2010) Assessment of Pregnancy Outcome in Primigravida: Comparison between Booked and Un-Booked Patients. Journal of Ayub Medical College Abbottabad, 22, 23-25.

[22] Latif, T., Ali, M.A., Majeed, A., Nahar, K. and Noor, Z. (2013) Labor Outcome of Primigravidae in Mymensingh Medical College Hospital. Mymensingh Medical Journal, 22, 432-437.

[23] Mustafa, M.H. and Mukhtar, A.M. (2015) Factors Associated with Antenatal and Delivery Care in Sudan: Analysis of the 2010 Sudan Household Survey. BMC Health Services Research, 15, 45. https://doi.org/10.1186/s12913-015-1128-1

[24] Hung, C.H. (2007) The Psychosocial Consequences for Primiparas and Multiparas. Kaohsiung Journal of Medical Science, 23, 352-360. https://doi.org/10.1016/S1607-551X(09)70421-8

[25] Bazant, E., Rakotovao, J.P., Rasolofomanana, J.R., Tripathi, V., Gomez, P., Favero, R., et al. (2013) Qualité des soins pour prévenir et traiter l'hémorragie du postpartum et la pré-éclampsie/éclampsie: Une évaluation fondée sur l'observation dans les hôpitaux de Madagascar [Quality of Care to Prevent and Treat Postpartum Hemorrhage and Preeclampsia/Eclampsia: An Observational Assessment in Madagascar's Hospitals]. Medecine et Sante Tropicales, 23, 168-175.

https://doi.org/10.1684/mst.2013.0161

[26] Kalala Tshingomba, D., Mutamba Mutondo, R., Mumba Mukandila, A., Ngiele Mpueta, A., Kalubi Nkole, D., Milongu Kasongoma, S., et al. (2016) La contraception par implant en milieux kasaïens: Fréquence et profil épidémiologique des utilisatrices. Revue Médicale des Grands Lacs, 6, 10-14.

[27] Kumar, R.T., Huda, M.N., Singh Brijesh, P. and Singh, K.K. (2015) Prevalence of Socioeconomic Correlates of Unplanned Pregnancy in Bangladesh. International Journal of Research in Economics and Social Sciences, 5, 183-195.

[28] Hamideh, B. and Maureen Heaman, R.N. (2011) Comparison of Demographic and Obstetric Characteristics of Canadian Primiparous Women of Advanced Maternal Age and Younger Age. Journal of Obstetrics and Gynaecology Canada, 33, 820-829. https://doi.org/10.1016/S1701-2163(16)34985-4

[29] You, H., Chen, J., Bogg, L., Wu, Y., Duan, S., et al. (2013) Study on the Factors Associated with Postpartum Visits in Rural China. PLOS ONE, 8, e55955. https://doi.org/10.1371/journal.pone.0055955

[30] Eleje, G.U., lgwegbe, A.O., Okonkwo, J.E., Udigwe, G.O. and Eke, A.C. (2014) Elderly Primigravidae versus Young Primigravidae: A Review of Pregnancy Outcome in a Low Resource Setting. Nigeria Journal of Medicine, 23, 220-229.

[31] Organisation mondiale de la Santé (2004) Prise en charge des complications de la grossesse et de l'accouchement: Guide destiné à la sage-femme et au médecin. OMS, Genève. 